\title{
Importância Das Dinâmicas de Grupos no Treinamento de Manipuladores de Alimentos
}

Consuelo Lúcia Sousa de Lima (I), Elisa Cristina Andrade Neves (I), Fabiane de Cássia Pontes Ramos (I), Jesus Nazareno Silva de

Souza (I), Carlos Augusto Teleck (I), Layra Lyz Rabelo (I)

(I) UFPA - Universidade Federal do Pará (Rua Augusto Corrêa, 01 - Guamá. CEP 66075-110. )

\section{Resumo}

Existe uma relação direta entre as condições higiênicas de manipuladores e doenças de origem alimentar por isso torna-se de extrema necessidade a aplicação de treinamentos constantes abordando assuntos diversos relacionados com a produção de alimentos seguros. Este trabalho teve como objetivo capacitar manipuladores de alimentos de um serviço de alimentação utilizando como ferramenta principal dinâmicas de grupo. $\mathrm{O}$ estudo foi realizado em um restaurante de Belém, que produz mais de 250 refeições diárias e contava com 20 funcionários. O treinamento de 8 horas foi realizado de maneira didática, sob forma de exposição teórica, áudiovisual e dinâmicas de grupo; abordando os temas relacionadas a manipulação segura de alimentos, sendo aplicado um mesmo questionário antes e após o treinamento. Para assimilação dos conteúdos foram realizadas dinâmicas sobre perigos, contaminação dos alimentos e mãos e uso de uniformes. Todos os manipuladores participaram do treinamento e a maioria tinha ensino médio completo $(71 \%)$. A receptividade por parte dos manipuladores durante os treinamentos foi bastante positiva, com frequentes sugestões sobre aspectos da rotina da produção. Na dinâmica de identificação de perigos, todos conseguiram discutir o tema abordado de forma descontraída, porém com discernimento sobre o assunto, visto que se expressaram buscando soluções práticas para a eliminação dos perigos no ambiente de trabalho. A dinâmica com purpurina demonstrou na prática, de 
forma eficiente, uma contaminação cruzada. Os manipuladores associaram a mesma aos micro-organismos e chegaram à conclusão, durante o debate, de que a higienização correta das mãos seria uma das formas para a solução do problema proposto. Quanto à dinâmica dos uniformes, observou-se motivação dos manipuladores a utilizar o uniforme completo, e, além disso, entenderam os motivos da utilização dos de: toucas, luvas e botas. Com a aplicação das dinâmicas, os manipuladores tiveram uma maior facilidade na assimilação de conceitos visto que tiveram a oportunidade de verificar a facilidade de contaminação dos alimentos e como medidas simples de higiene poderiam ter evitado essas contaminações. Em relação à aplicação dos questionários antes e após o treinamento, verificou-se aumento de 35\% de acertos. $\mathrm{O}$ treinamento aliado às dinâmicas de grupo foi eficiente para capacitação e compreensão dos assuntos abordados.

Palavras-Chave: Capacitação, Contaminação, Higiene, Restaurante Agência de Fomento: 